\title{
Validation of suitable endogenous control genes for quantitative PCR analysis of microRNA gene expression in a rat model of endometrial cancer
}

\author{
Sanja Jurcevic ${ }^{1}$, Björn Olsson ${ }^{2}$ and Karin Klinga-Levan ${ }^{1 *}$
}

\begin{abstract}
Background: MicroRNAs are small RNA molecules that negatively regulate gene expression by translational inhibition or mRNA cleavage. The discovery that abnormal expression of particular miRNAs contributes to human disease, including cancer, has spurred growing interest in analysing expression profiles of these molecules. Quantitative polymerase chain reaction is frequently used for quantification of miRNA expression due to its sensitivity and specificity. To minimize experimental error in this system an appropriate endogenous control gene must be chosen. An ideal endogenous control gene should be expressed at a constant level across all samples and its expression stability should be unaffected by the experimental procedure.

Results: The expression and validation of candidate control genes (4.5S RNA(H) A, Y1, 4.5S RNA(H) B, snoRNA, U87 and U6) was examined in 21 rat cell lines to establish the most suitable endogenous control for miRNA analysis in a rat model of cancer. The stability of these genes was analysed using geNorm and NormFinder algorithms. U87 and snoRNA were identified as the most stable control genes, while Y1 was least stable.
\end{abstract}

Conclusion: This study identified the control gene that is most suitable for normalizing the miRNA expression data in rat. That reference gene will be useful when miRNAs expression are analyzed in order to find new miRNA markers for endometrial cancer in rat.

Keywords: Endogenous control genes, microRNA, Endometrial cancer

\section{Background}

Endometrial cancer is the most frequently diagnosed gynaecological malignancy in the western world. According to the World Cancer Research Fund (WCRF) around 288000 women worldwide develop endometrial cancer annually and 74. 000 died from this cancer in 2008 [1]. This malignancy can be divided into two different types, endometrioid adenocarcinoma (type I) and serous carcinoma (type II). Type I develops from endometrial hyperplasia and is characterized by oestrogen dependence, well differentiated cells, and good prognosis. Type II, on the other hand, develops from atrophic endometrium and is oestrogen independent, with poorly differentiated cells, and has poor prognosis. The most common type, endometrioid adenocarcinoma (EAC),

\footnotetext{
* Correspondence: karin.klinga.levan@his.se

'Systems Biology Research Centre, Tumor Biology, School of Life Sciences,

Skovde, Sweden

Full list of author information is available at the end of the article
}

accounts for approximately $75 \%$ of the reported cases $[2,3]$. As all cancers, EAC is a complex disease, where interactions between genes and environment play important roles in the course of the disease. Studies of such diseases are complicated due to the genetic heterogeneity and environmental diversity of the human population, and therefore inbred animal model systems are often used to minimize the genetic diversity and to control the environmental factors [4]. The use of animal models does, however, not replace research on human material; these complement each other.

Virgin females of the BDII/Han inbred rat strain spontaneously develop EAC at a frequency of more than $90 \%$ during their lifetime $[5,6]$. Due to the high degree of conservation between the human and rat genomes, genetic aberrations in the BDII rat can be used to predict alterations associated with EAC development in humans. The similarities in physiology and pathogenesis between rats and humans imply that the BDII 
rat strain is a suitable model for analysis of human endometrial cancer [7].

MicroRNAs (miRNAs) are small RNA molecules that regulate gene expression by inhibition of protein translation or by degradation of their target mRNAs. It is estimated that up to $30 \%$ of human genes are regulated by miRNAs [8], and it has been shown that the functions of the target genes include a broad range of important biological processes, such as development, differentiation, growth and metabolism [9]. As for most cancers certain miRNAs are differentially expressed in EAC compared to normal tissue (see ref. [10] for a review). However, to our knowledge, no such miRNA expression analysis has yet been done in models of EAC in rat.

Due to its sensitivity and specificity quantitative polymerase chain reaction (qPCR) is commonly used for miRNA expression analysis [11]. The data from qPCR can be analysed and presented as absolute or relative values. In absolute quantification a standard curve is used to calculate the quantity of the unknown sample, whereas relative quantification is based on the relative expression of the gene of interest compared to one or more reference genes [12]. For relative quantification methods, raw qPCR data are normalized in order to correct for variation caused by the amount of starting material, variation in reaction efficiency and sample purity. This normalization can be done using one or more stably expressed endogenous control genes. A gene that is used as a reference must have stable expression independent of sample and tissue type [13]. In most qPCR studies of miRNA expression small nuclear and/or nucleolar RNAs have been used as control genes, but there are also studies in which stably expressed miRNAs have been used. There are several reasons why small non-coding RNA genes might be well suited as controls for normalizing miRNA expression data, including their stable expression, such as the nucleotide size, and the use of identical assay chemistry $[14,15]$. Several human and mouse small RNAs have been tested and confirmed as suitable endogenous controls for quantification of miRNA expression levels [14], but as far as we know no such study has yet been performed for small RNAs in rat.

In this study, six endogenous control genes were selected and tested for expression stability in tissues derived from rat endometrium; five small nuclear RNAs and one small cytoplasmic RNA. The identification of suitable endogenous control genes is an important initial step in expression analysis since usage of an unstable control gene for normalization could result in misleading conclusions.

\section{Results}

Differences between the triplicates were tested for significance by ANOVA $(\mathrm{p}<0.05)$, which revealed no significant differences between the three replicates in any of the six endogenous controls. Student's $t$-test were applied for differences in gene expression between malignant and non-/pre-malignant samples were tested for in each of the six candidate genes using the (Table 1). No significant difference in expression between malignant and non-/premalignant samples was detected for 4.5S RNA (H) A, 4.5S RNA $(\mathrm{H}) \mathrm{B}$, snoRNA and U87, but significant differences were found for U6 and $\mathrm{Y} 1(\mathrm{p}<0.05)$.

In order to identify and rank the most suitable control genes the data were analysed by two different algorithms, geNorm and NormFinder. GeNorm calculates the stability values $(M)$ for all candidate genes, then eliminates the candidate gene with the highest $M$ and repeats this procedure until the two most stable genes are left. The analysis revealed that all genes showed $M$-values below the geNorm default limit of 1.5 (Table 1). The control genes with the lowest $M$-values and highest expression stability were U6 and 4,5S RNA (H) A, both with $M=0.714$. U87 was the third most stably expressed gene with $M=0.797$. NormFinder calculates a stability value (standard deviation, SD) for each gene, where a low SD represents more stable expression (Table 1). In contrast to geNorm, Normfinder identified U87 and snoRNA as the two most stable genes with $\mathrm{SD}=0.611$ and 0.662 , respectively. Although the two rankings differ, both algorithms identified $\mathrm{Y} 1$ as the most unstable gene.

When more than one control gene is identified by Normfinder, this algorithm will also calculate the accumulated standard deviation. The optimal number of control genes is indicated by the lowest value for the accumulated $\mathrm{SD}$. For this data the lowest value is reached when five control genes are used and all of them are nuclear RNAs, whereas the excluded gene (Y1) is cytoplasmic (Table 2, Figure 1).

\section{Discussion}

It has been clearly demonstrated in numerous studies that miRNAs play critical roles in the development of

\begin{tabular}{|c|c|c|c|c|c|c|c|}
\hline \multirow[b]{2}{*}{ Control gene } & \multicolumn{2}{|c|}{$t$-test* } & \multicolumn{2}{|c|}{ geNorm } & \multicolumn{2}{|c|}{ NormFinder } & \multirow[b]{2}{*}{ Total rank } \\
\hline & $P$ value & Rank & $M$ & Rank & SD & Rank & \\
\hline U87 & 0.158 & 3 & 0.797 & 3 & 0.611 & 1 & 1 \\
\hline snoRNA & 0.937 & 1 & 0.948 & 4 & 0.662 & 2 & 1 \\
\hline 4,5S RNA(H) A & 0.194 & 2 & 0.714 & 2 & 0.886 & 5 & 3 \\
\hline U6 & 0.023 & 6 & 0.714 & 1 & 0.696 & 3 & 4 \\
\hline 4,5S RNA(H) B & 0.373 & 4 & 1.016 & 5 & 0.773 & 4 & 5 \\
\hline Y1 & 0.032 & 5 & 1.152 & 6 & 1.255 & 6 & 6 \\
\hline
\end{tabular}

*The $t$-test refers to differences in gene expression between malignant and non-/pre-malignant samples. 
Table 2 Panel of cell lines that were used in the present study

\begin{tabular}{|c|c|c|}
\hline Tumour & Genetic background & Pathology \\
\hline NUT6 & $(\mathrm{BD} \| \times \mathrm{BN}) \times \mathrm{BD} \|$ & EAC \\
\hline NUT43 & $(\mathrm{BD} \| \times \mathrm{BN}) \times \mathrm{BD} \|$ & EAC \\
\hline NUT50 & $(\mathrm{BD} \| \times \mathrm{BN}) \times \mathrm{BD} \|$ & EAC \\
\hline NUT81 & $(\mathrm{BD} \| \times \mathrm{BN}) \times \mathrm{BD} \|$ & EAC \\
\hline NUT128 & $(\mathrm{BD} \| \times \mathrm{BN}) \times \mathrm{BD} \|$ & EAC \\
\hline NUT48 & $(\mathrm{BD} \| \times \mathrm{BN}) \times \mathrm{BD} \|$ & NME \\
\hline NUT75 & $(\mathrm{BD} \| \times \mathrm{BN}) \times \mathrm{BD} \|$ & NME \\
\hline NUT110 & $(\mathrm{BD} \| \times \mathrm{BN}) \times \mathrm{BD} \|$ & NME \\
\hline NUT122 & $(\mathrm{BD} \| \times \mathrm{BN}) \times \mathrm{BD} \|$ & NME \\
\hline NUT129 & $(\mathrm{BD} \| \times \mathrm{BN}) \times \mathrm{BD} \|$ & NME \\
\hline NUT7 & $(\mathrm{BD} \| x \mathrm{SPRD}) \times \mathrm{BD} \|$ & EAC \\
\hline NUT41 & $(B D \| x S P R D) \times B D \|$ & EAC \\
\hline NUT42 & $(B D \| x S P R D) \times B D \|$ & EAC \\
\hline NUT47 & (BD\|xSPRD)xBD\| & EAC \\
\hline NUT84 & $(\mathrm{BD} \| x \mathrm{SPRD}) \times \mathrm{BD} \|$ & EAC \\
\hline NUT58 & $(B D \| x S P R D) \times B D \|$ & NME \\
\hline NUT68 & $(B D \| x S P R D) \times B D \|$ & NME \\
\hline NUT74 & (BD\|xSPRD)xBD\| & NME \\
\hline NUT89 & $(B D \| x S P R D) \times B D \|$ & NME \\
\hline NUT91 & $(\mathrm{BD} \| x \mathrm{SPRD}) \times \mathrm{BD} \|$ & NME \\
\hline
\end{tabular}

The tumour material was derived from cross between females from the EACsusceptible BDIl strain and males from BN or SPRD, respectively. NUT- tumour developed in the backcross (N1) progeny.

cancer [16,17]. The first documentation of a miRNA abnormality in cancer was reported by Croce and colleagues in 2002, who found that two miRNAs, miR-15 and miR-16, were lost or down-regulated in most patients with chronic lymphocytic leukaemia (CLL) [18]. Furthermore, altered miRNA expression profiles have been reported in other cancers, such as colon [19], breast [20] and endometrial cancer [21]. Identification of deregulated miRNAs in different cancer types, and knowledge of their functional significance, will advance

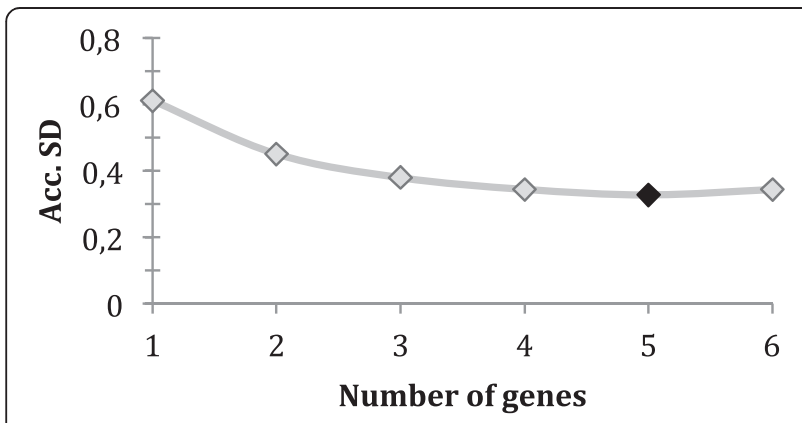

Figure 1 Accumulated SD using NormFinder, indicating five reference genes (black marker) as the optimal choice. our understanding of the aetiology of cancer and ultimately lead to development of valuable therapeutic tools.

Quantitative polymerase chain reaction (qPCR) is one of the most important methods used for gene expression analysis, since it is highly specific and allows quantitative detection of small changes in gene expression. One of the most critical points in determination of a reliable expression pattern is removal of non-biological (experimental) variation from true biological variation. The factors that influence the variability of qPCR expression values include the amount and quality of the starting material, the yields of the extraction process and the reaction efficiency. To deal with these factors it is important to use a suitable normalization strategy in the data analysis. The commonly used option for normalization is to use stably expressed endogenous control genes [22].

A suitable endogenous control gene should have abundant and constant expression across all samples. I would be very advantageous to identify control genes that are stably expressed independent of cell type and tissue type. Since no such control gene has been identified, it is important to validate the expression of endogenous control genes [13]. A good endogenous control for normalization of miRNA expression data must share similar properties with miRNAs, such as the size and stability of the RNA molecule. Some classes of small non-coding RNAs, not belonging to the miRNA class, are often expressed in an abundant and stable manner, making them good candidate control genes [14,15].

While many endogenous controls for miRNA expression studies have been identified in different species such as human and pigs [23,24], no well-established endogenous controls for miRNA quantification have been identified in rat. One of the endogenous control genes that we identified as a suitable in this report, the U6 snRNA, has been used as a reference gene in recently published studies on lung cancer [25].

In this study, we investigated the expression of $4.5 \mathrm{~S}$ RNA (H) A, Y1, 4.5S RNA (H) B, snoRNA U87 and U6 in 21 rat cell lines. NormFinder and geNorm were used to find suitable control genes from this set of candidates, and both algorithms identified the same five control genes as most stably expressed, only differing in their ranking order. This is not unexpected since the two algorithms use different mathematical models. GeNorm calculates the stability value defined as the arithmetic mean of all pair-wise comparisons, whereas NormFinder estimates both the overall expression variation as well as the variation between sample groups. Therefore, the results of this study indicate that $\mathrm{Y} 1$ should not be used as endogenous control since it is ranked as the least stable by both algorithms. It is noteworthy that the five most stable genes in this study are all expressed in the nucleus, while Y1 is expressed in the cytoplasm. The 
Student's $t$-test gives an additional clue to the stability of the endogenous control genes, where genes with the highest $p$ values would be the most stable ones (Table 1).

Beside the stability values, NormFinder also calculates the accumulated standard deviation, which determines the number of reference genes that should be used for normalization. The results from NormFinder indicate that use of the five most stable genes (U6, 4,5S RNA $(\mathrm{H})$ A, U87, snoRNA and 4,5S RNA (H) B) provides the best normalization. However, using five reference genes would be both time consuming and expensive as well as require a lot of starting material. It may therefore be advantageous to use snoRNA and U87, which are highly ranked by both algorithms, as well as by the $t$-test.

\section{Conclusion}

In summary, careful selection of appropriate endogenous control genes plays a crucial role in expression studies. The candidate endogenous control genes should be validated, because a gene that is stable in one cell line or tissue type is not necessarily stable in other cell lines/tissue types. We recommend use of U87 and snoRNA as control genes in miRNA expression analysis in rat cells.

\section{Materials and methods}

\section{Tumour material}

In a previous study females from the EAC-susceptible BDII strain were crossed to males from two other inbred rat strains that are not prone to develop EAC, $\mathrm{BN} / \mathrm{Han}$ and SPRD-Cu3/Han (hereafter BN and SPRD). An F1 generation was generated and the F1 progenies were either backcrossed to BDII females to generate an $\mathrm{N} 1$ generation, or intercrossed to produce F2 progeny. Tumour formation was monitored by palpation. In cases of suspected tumour, the animals were sacrificed and a necropsy was done. Pathological analysis showed that the majority of the tumours that developed in the N1 progeny were classified as EAC, but in some cases no malignant cells were observed in the removed cell mass. These tissue samples were classified as non-/premalignant endometrium [26]. Spontaneously arising tumours developed in approximately $25 \%$ of the F1, F2 and N1 offspring [27,28]. The NUT (backcross
(N1) uterine tumour)specimens represent non-/premalignant cells (NME) from the endometrium or endometrial adenocarcinomas (EAC) developed in the backcross (N1) progeny.

In the present study, a total of 20 NUT endometrial cell lines were studied, of which 10 were classified as NME and 10 as EAC. Ten of the cell lines were derived from the (BNxBDII)xBDII crosses and ten from the (SPRDxBDII)xBDII crosses (Table 2). A rat embryo fibroblast (REF) cell culture was used as normal control.

\section{Cell cultures}

The cell lines established from endometrial adenocarcinoma and non-/pre-malignant tissues were cultured in Dulbecco's modified Eagle medium (DMEM) supplemented with $10 \%$ heat-inactivated fetal bovine serum, $100 \mathrm{IU} /$ $100 \mu \mathrm{g} \mathrm{ml}-1$ penicillin/streptomycin, L-glutamine, MEM essential and non-essential amino acids, and MEM vitamins solution. The cells were grown at $37^{\circ} \mathrm{C}$ in an atmosphere of $95 \%$ humidity and $5 \% \mathrm{CO}_{2}$. The cells were harvested by trypsinization at $80-90 \%$ confluence $\left(<1 \times 10^{6}\right.$ cells $)$.

\section{Candidate control genes}

A total of six candidate endogenous control genes were selected based on the availability of commercial primers. They are all small non-coding RNAs; five small nuclear RNAs (4.5S RNA (H) A, 4.5S RNA (H) B, snoRNA, U87 and U6) and one small cytoplasmic RNA (Y1). Details regarding the selected RNAs are listed in Table 3.

\section{RNA extraction, reverse transcription and $\mathrm{qPCR}$}

Total RNA including miRNA was isolated from the cell lines using a mirVana miRNA Isolation Kit (Ambion) following the manufacturer's protocol. Quality and quantity of the RNA samples were determined in a NanoDrop ND-1000 Spectrophotometer (NanoDrop Technologies, USA). All the RNA samples had a 260/280 absorbance ratio of 2.0-2.1. Total RNA samples were converted to cDNA and aliquoted into triplicates using TaqMan microRNA reverse transcription kit and TaqMan miRNA primers (Applied Biosystems). After the RT step, the realtime PCR reactions were performed according to the manufacturer's instructions; the reaction consisted of $1.33 \mu \mathrm{l}$ cDNA (10 ng), $1.0 \mu \mathrm{l}$ TaqMan Small RNA Assay

Table 3 Candidate control genes selected for evaluation of expression stability

\begin{tabular}{|c|c|c|c|c|}
\hline Assay name & Name & Accession no & Type of RNA & Database \\
\hline 4.5S RNA(H) A & 4.5S RNA(H) variant 5 & AY228151 & snRNA & GenBank \\
\hline Y1 & Y1 scRNA gene & U84683 & scRNA & GenBank \\
\hline 4.5S RNA(H) B & 4.5S RNA(H) variant 1 & AY228147 & snRNA & GenBank \\
\hline snoRNA & E2 small nucleolar RNA gene & U64702 & snRNA & GenBank \\
\hline U87 & small nucleolar RNA U87 & AF272707 & snRNA & GenBank \\
\hline U6 & U6 small nuclear 1 (RNU6-1) & NR_004394 & snRNA & RefSeq \\
\hline
\end{tabular}


(20X), $10 \mu \mathrm{l}$ TaqMan Universal PCR Master Mix II and $7.67 \mu 1$ nuclease-free water. All reactions were performed in triplicates, including the no-template control (NTC). The reactions were run on an Applied Biosystems 7300 Real Time PCR system with the following thermal cycles: one cycle of $95^{\circ} \mathrm{C}$ for 10 minutes; 40 cycles with a denaturation step at $95^{\circ} \mathrm{C}$ for 15 seconds and an annealing/extension step at $60^{\circ} \mathrm{C}$ for 60 seconds.

\section{Data analysis}

Relative quantities for each candidate gene were calculated using the comparative $\mathrm{Ct}$ method. The $\mathrm{Ct}$ value represents the cycle number at which the fluorescence passes the defined threshold. One-way analysis of variance (ANOVA) was used to test for any significant difference among replicates $(\mathrm{p}<0.05)$. Differences in gene expression between malignant and non-/pre-malignant samples were calculated by the Student's $t$-test $(\mathrm{p}<0.05)$.

GenEx software (MultiD Analyses AB, Göteborg, Sweden) was used to analyze the stability of candidate genes with the geNorm and NormFinder algorithms. GeNorm calculates, for each candidate control gene, the pairwise variation with all other candidate genes as the standard deviation of the log-transformed expression ratios, followed by calculation of the $M$-value. The $M$-value describes the average pairwise variation for a particular control gene with all other candidate genes. At each comparison the gene that shows largest variation to all the genes is eliminated. The process is repeated until there is only one pair of genes left. These last two genes are recommended as the optimum control genes [29].

NormFinder calculates the variance of gene expression both within groups and between groups (such as normal vs cancer). The intra- and intergroup variances are combined into a single stability value and the algorithm ranks the candidate control genes according to this combined variance. The main differences between geNorm and NormFinder are that NormFinder takes into account both the inter- and intragroup variation [30].

\section{Abbreviations \\ miRNA: microRNA; EAC: Endometrioid adenocarcinoma; NME: Non-/pre- malignant cells; qPCR: Quantitative polymerase chain reaction.}

\section{Competing interests}

The authors declare that they have no competing interests.

\section{Authors' contributions}

SJ performed all the experiments and data analysis and helped to draft the manuscript. KKL and BO participated in the analysis of data as well as helped to draft the manuscript. All authors read and approved the final manuscript.

\section{Funding}

This work was supported by the Swedish Knowledge Foundation (grant no 2009/091), Nilsson-Ehle Foundation, the Wilhelm and Martina Lundgren Foundation, and Örebro University.

\section{Author details}

${ }^{1}$ Systems Biology Research Centre, Tumor Biology, School of Life Sciences, Skovde, Sweden. ${ }^{2}$ Systems Biology Research Centre, Bioinformatics, School of Life Sciences, University of Skövde, Skovde, Sweden.

Received: 7 December 2012 Accepted: 13 May 2013 Published: 16 May 2013

\section{References}

1. Ferlay J, Shin HR, Bray F, Forman D, Mathers C, Parkin DM: Estimates of worldwide burden of cancer in 2008: GLOBOCAN 2008. Int J Cancer 2010, 127(12):2893-2917.

2. Cavanagh D, Fiorica J, Hoffman M, Durfee J, Nicosia S: Adenocarcinoma of the endometrium: an institutional review. Cancer Control 1999, 6(4):354-360.

3. Emons G, Fleckenstein G, Hinney B, Huschmand A, Heyl W: Hormonal interactions in endometrial cancer. Endocr Relat Cancer 2000, 7(4):227-242.

4. Gill TJ III, Smith GJ, Wissler RW, Kunz HW: The rat as an experimental animal. Science 1989, 245(4915):269-276.

5. Kaspareit-Rittinghausen J, Deerberg F, Rapp K: Mortality and incidence of spontaneous neoplasms in BDII/Han rats. Z Versuchstierkd 1987, 30(5-6):209-216.

6. Deerberg FKJ: Endometrial Carcinoma in BDII/Han rats: model of a spontaneous hormone-dependent tumor. J Natl Cancer Inst 1987, 78(6):1245-1251.

7. Vollmer G: Endometrial cancer: experimental models useful for studies on molecular aspects of endometrial cancer and carcinogenesis. Endocr Relat Cancer 2003, 10(1):23-42.

8. Stahlhut ECE, Slack F: The role of microRNAs in cancer. Yale J Biol Med 2006, 79(3-4):131.

9. Krützfeldt J, Poy MN, Stoffel M: Strategies to determine the biological function of microRNAs. Nat Genet 2006, 38:S14-S19.

10. Devor EJ, Goodheart MJ, Leslie KK: Toward a microRNA signature of endometrial cancer. Proceedings in Obstetrics and Gynecology 2011, 2(1):1-7.

11. Chen C, Ridzon DA, Broomer AJ, Zhou Z, Lee DH, Nguyen JT, Barbisin M, Xu NL, Mahuvakar VR, Andersen MR, Lao KQ, Livak KJ, Guegler KJ: Real-time quantification of microRNAs by stem-loop RT-PCR. Nucleic Acids Res 2005, 33(20):e179.

12. Yuan J, Reed A, Chen F, Stewart CN: Statistical analysis of real-time PCR data. BMC Bioinformatics 2006, 7(1):85

13. Huggett J, Dheda K, Bustin S, Zumla A: Real-time RT-PCR normalisation; strategies and considerations. Genes Immun 2005, 6(4):279-284.

14. Wong L, Lee K, Russell I, Chen C: Endogenous controls for real-time quantitation of miRNA using TaqMan ${ }^{\oplus}$ MicroRNA assays. http://www. appliedbiosystems.com.

15. Finnegan EJ, Matzke MA: The small RNA world. J Cell Sci 2003, 116(23):4689-4693.

16. Barbarotto E, Schmittgen TD, Calin GA: MicroRNAs and cancer: profile, profile, profile. Int J Cancer 2008, 122(5):969-977.

17. Calin GA, Croce CM: MicroRNA signatures in human cancers. Nat Rev Cancer 2006, 6(11):857-866

18. Calin GA, Dumitru CD, Shimizu M, Bichi R, Zupo S, Noch E, Aldler H, Rattan $S$, Keating M, Rai K: Frequent deletions and down-regulation of microRNA genes miR15 and miR16 at 13q14 in chronic lymphocytic leukemia. Proc Natl Acad Sci 2002, 99(24):15524.

19. Schee K, Fodstad $\varnothing$, Flatmark K: MicroRNAs as biomarkers in colorectal cancer. Am J Pathol 2010, 177(4):1592

20. Iorio MV, Ferracin M, Liu CG, Veronese A, Spizzo R, Sabbioni S, Magri E, Pedriali M, Fabbri M, Campiglio M: MicroRNA gene expression deregulation in human breast cancer. Cancer Res 2005, 65(16):7065.

21. Chung TKH, Cheung T-H, Huen N-Y, Wong KWY, Lo KWK, Yim S-F, Siu NSS, Wong Y-M, Tsang P-T, Pang M-W, Yu M-Y, To K-F, Mok SC, Wang WW, Li C, Cheung AYK, Doran G, Birrer MJ, Smith DI, Wong Y-F: Dysregulated microRNAs and their predicted targets associated with endometrioid endometrial adenocarcinoma in Hong Kong women. Int J Cancer 2009, 124(6):1358-1365.

22. Vandesompele J, Kubista M, Pfaffl MW: Reference gene validation software for improved normalization. In Real-time PCR: current technology and applications. 1st edition. Edited by Logan J, Edwards K, Saunders N. Norfolk: Caister Academic Press; 2009:47-64. 
23. Schaefer A, Jung M, Miller K, Lein M, Kristiansen G, Erbersdobler A, Jung K: Suitable reference genes for relative quantification of miRNA expression in prostate cancer. Exp Mol Med 2010, 42(11):749.

24. Gu Y, Li M, Zhang K, Chen L, Jiang AA, Wang J, Lv X, Li X: Identification of suitable endogenous control microRNA genes in normal pig tissues. Anim Sci J 2011, 82(6):722-728.

25. Roa W, Brunet B, Guo L, Amanie J, Fairchild A, Gabos Z, Nijjar T, Scrimger R, Yee $D$, Xing J: Identification of a new microRNA expression profile as a potential cancer screening tool. Clin Invest Med 2010, 33(2):E124-E132.

26. Karlsson S, Olsson B, Klinga-Levan K: Gene expression profiling predicts a three-gene expression signature of endometrial adenocarcinoma in a rat model. Cancer Cell Int 2009, 9:12.

27. Roshani L, Wedekind D, Szpirer J, Taib Z, Szpirer C, Beckman B, Rivière M, Hedrich HJ, Klinga-Levan K: Genetic identification of multiple susceptibility genes involved in the development of endometrial carcinoma in a rat model. Int $J$ Cancer 2001, 94(6):795-799.

28. Roshani L, Mallon P, Sjostrand E, Wedekind D, Szpirer J, Szpirer C, Hedrich $\mathrm{HJ}$, Klinga-Levan K: Genetic analysis of susceptibility to endometrial adenocarcinoma in the BDII rat model. Cancer Genet Cytogenet 2005, 158(2):137-141.

29. Vandesompele J, De Preter K, Pattyn F, Poppe B, Van Roy N, De Paepe A, Speleman F: Accurate normalization of real-time quantitative RT-PCR data by geometric averaging of multiple internal control genes. Genome Biol 2002, 3(7):RESEARCH0034.

30. Andersen $C L$, Jensen JL, Orntoft TF: Normalization of real-time quantitative reverse transcription-PCR data: a model-based variance estimation approach to identify genes suited for normalization, applied to bladder and colon cancer data sets. Cancer Res 2004, 64(15):5245-5250.

doi:10.1186/1475-2867-13-45

Cite this article as: Jurcevic et al.: Validation of suitable endogenous control genes for quantitative PCR analysis of microRNA gene expression in a rat model of endometrial cancer. Cancer Cell International 2013 13:45

\section{Submit your next manuscript to BioMed Central and take full advantage of:}

- Convenient online submission

- Thorough peer review

- No space constraints or color figure charges

- Immediate publication on acceptance

- Inclusion in PubMed, CAS, Scopus and Google Scholar

- Research which is freely available for redistribution 